Al-Kharaj: Jurnal Ekonomi, Kenangan \& Bisnis Syariah

Volume 4 No 3 (2022) 914-933 P-ISSN 2656-2871 E-ISSN 2656-4351

DOI: 10.47467/alkharaj.v4i3.751

\title{
Analisis Peran Motivasi sebagai Mediasi Pengaruh Trilogi Kepemimpinan dan Kepuasan Kerja terhadap Produktivitas Kerja Karyawan: PT. Mataram Tunggal Garment
}

\author{
Willis Gita Kinasis, Didik Subiyanto, Epsilandri Septyarini \\ Universitas Sarjanawiyata Tamansiswa \\ willisgita20@gmail.com,didiks@ustjogja.ac.id, epsilandriseptyarini@ustjogja.ac.id
}

\begin{abstract}
The purpose of this study is to find out the motivation to mediate the leadership trilogy and job satisfaction to employee work productivity at PT. Mataram Tunggal Garment. The method used in this study is quantitative. Primary data was obtained from questionnaires with 78 respondents with saturated sample techniques. Then the data is analyzed using descriptive analysis, multiple linear regression tests, $t$ (partial) tests, coesifisien determination $(R 2)$ and sobel tests. The results showed that job satisfaction had a significant influence on motivation, leadership trilogy and job satisfaction had a significant influence on employee work productivity, leadership trilogy and motivation had no significant effect on employee work productivity, motivation mediated leadership trilogy and job satisfaction had no insignificant effect on employee work productivity.
\end{abstract}

Keywords: Leadership Trilogy, Motivation, Job Satisfaction and Employee Productivity.

ABSTRAK.

Tujuan penelitian ini merupakan mengetahui motivasi memediasi trilogi kepemimpinan serta kepuasan kerja terhadap produktivitas kerja karyawan pada PT. Mataram Tunggal Garment. Metode yang digunakan dalam penelitian ini adalah kuantitatif. Data primer diperoleh dari kuesioner dengan 78 responden dengan teknik sampel jenuh. Kemudian data dianalisis dengan menggunakan analisis deskriptif, uji regresi linier berganda, uji t (parsial), koesifisien determinasi (R2) dan uji sobel. Hasil penelitian menunjukkan bahwa kepuasan kerja terdapat pengaruh signifikan terhadap motivasi, trilogi kepemimpinan dan kepuasan kerja terdapat pengaruh signifikan terhadap produktivitas kerja karyawan, trilogi kepemimpinan dan motivasi berpengaruh tidak signifikan terhadap produktivitas kerja karyawan, motivasi memediasi trilogi kepemimpinan dan kepuasan kerja terdapat pengaruh tidak signifikan terhadap produktivitas kerja karyawan.

Kata kunci: Trilogi kepemimpinan, Motivasi, Kepuasan kerja dan Produktivitas Kerja Karyawan. 


\section{Al-Kharaj: Jurual Ékonomi, Kenanczan \& Bisnis Syariah \\ Volume 4 No 3 (2022) 914-933 P-ISSN 2656-2871 E-ISSN 2656-4351 \\ DOI: 10.47467/alkharaj.v4i3.751}

\section{PENDAHULUAN}

Manajemen Sumber Daya Manusia (SDM) merupakan hal yang sangat penting untuk mencapai tujuan perusahaan. Sumber daya manusia di era globalisasi disertai dengan kemajuan yang signifikan dalam kondisi ekonomi. Untuk dapat bertahan, perusahaan dapat menggunakan keunggulannya untuk bersaing. Keunggulan perusahaan berasal dari faktor produksi perusahaan yaitu material, mesin, serta sumber daya manusia. Sebagai salah satu faktor produksi, manusia merupakan aset yang sangat penting bagi kelangsungan hidup perusahaan. Orang menjadi motor penggerak dan menentukan proses organisasi, sehingga perlu mendapat perhatian dari pimpinan.

Kepemimpinan dalam organisasi harus pasti sangat erat kaitannya dengan kepemimpinan Ki Hadjar Dewantara, pendiri Universitas Sarjananwiyata Tamansiswa, lahir pada tanggal 2 Mei 1889 di Yogyakarta merupakan Trilogi Kepemimpinan. Teori kepemimpinan yang terdiri dari tiga unsur yaitu "ing ngarso sung tuladha, ing madya mangun karsa, tut wuri handayani" telah banyak berkembang di kalangan masyarakat. Hal ini menunjukkan bahwa citra seorang pemimpin harus memberikan teladan bagi bawahannya, tetapi juga memberikan dorongan dan semangat bagi bawahannya (Ahyar, 2018).

Kepuasan kerja merupakan faktor penting yang harus dibentuk dilikungan kerja, karena kepuasan kerja akan mempengaruhi produktivitas kerja seseorang Ninla Elmawati Falabiba, (2019). Artinya agar mencapai keberhasilan bisa dicapai menggunakan cara mengelola sumber daya manusia semaksimal mungkin, sebab sumber daya manusia yang berkualitas merupakan keunggulan perusahaan dalam mencapai tujuan, salah satunya adalah meningkatkan produktivitas karyawan.

Menurut Hasibuan produktivitas kerja adalah perbandingan antara masuk dan keluarnya suatu kegiatan dan pengunaan sumber daya yang baik diprioritaskan ketika menghasilkan barang atau jasa Karima et al., (2018). Produktivitas karyawan merupakan hal yang sangat penting dalam suatu perusahaan, untuk mencapainya dengan sebaikbaiknya fokus pada kepuasan kerja karyawan.

Selain kepuasan kerja, perusahaan wajib memperhatikan bagaimana menjaga dan mengelola semangat karyawan dalam bekerja, supaya selalu berada di posisi yang tinggi serta mengutamakan tujuan perusahaan. Menjaga motivasi karyawan itu sangatlah penting sebab mereka yang mengambil tindakan dan melakukan sesuatu Kerja et al., (2014). Mengingat pentingnya insentif, perhatian pihak manajemen terhadap masalah insentif karyawan di tempat kerja sesuai dengan kebijakan perusahaan melalui serangkaian kerja keras, bonus dan tindakan insetif tertentu lainnya untuk memotivasi karyawan perusahaan untuk melakukan bisnis, sehingga untuk menjaga semangat kerja karyawan. 


\section{A1-Kharaj: Jurual Ekonomi, Kenangan \& Bisnis Syariah \\ Volume 4 No 3 (2022) 914-933 P-ISSN 2656-2871 E-ISSN 2656-4351 \\ DOI: 10.47467/alkharaj.v4i3.751}

\section{METODE PENELITIAN}

\section{Sifat Penelitian}

Penelitian ini bertujuan untuk menggunakan metode penelitian kuantitatif sebab data penelitian berupa angka-angka yang nantinya akan dianalisis menggunakan statistik penelitian ini. Penelitian ini untuk mengetahui analisis peran motivasi sebagai mediasi pengaruh trilogi kepemimpinan dan kepuasan kerja terhadap produktivitas kerja karyawan di PT. Mataram Tunggal Garment, Yogyakarta.

\section{Populasi dan Teknik Pengambilan sampel}

Populasi pada penelitian ini merupakan seluruh karyawan pada bagian produksi di PT. Mataram Tunggal Garment, Sleman, Yogyakarta dimana jumlah populasinya 78 orang karyawan. Penelitian ini menggunakan sampel jenuh atau biasa disebut sensus. Alasan memilih sampel jenuh karena populasi tidak mencukupi 100 orang. Berdasarkan penelitian ini karena jumlah populasi hanya 78 orang responden, maka peneliti menggambil 100\% jumlah populasi yang ada dengan jumlah populasi 78 orang di PT. Mataram Tunggal Garment, Yogyakarta diambil sebagai sampel penelitian.

Pada penelitian ini data yang diperlukan sudah ada data yang dengan seksama serta dapat terpercaya kebenarannya, dan dapat memberikan informasi yang tepat bagi peneliti. Data yang diperlukan didasarkan pada sumbernya, yaitu data primer yang diperoleh dari sumber primer yaitu dengan menggunakan kuesioner yang dilakukan secara langsung terhadap objek yang diteliti untuk memperoleh jawaban langsung dari responden.

\section{Tempat dan Waktu Pengambilan Data}

Tempat pengambilan data langsung di PT. Mataram Tunggal Garment, Ngaglik, Sleman, D.I Yogyakarta. Waktu pengambilan data penelitian ini Agustus 2021.

\section{HASIL DAN PEMBAHASAN}

\section{Uji Validitas dan Reabilitas}

Untuk tingkat validitas dilakukan uji signifikansi dengan membandingkan nilai $r_{\text {hitung }}$ dengan nilai $r_{\text {tabel }}$. Hasil uji validitas yang di dapatkan $r_{\text {tabel }}$ sebesar 0,1876. Jika $r_{\text {hitung }}>r_{\text {tabel }}$ maka butir pernyataan tersebut dikatakan valid.

Uji Reabilitas untuk ke 4 Variabel penelitian menggunakan dapat dilihat hasil uji statistik Cronbach's Alpha Based on Standarized Item.

\section{Tabel 1}

Uji Reabilitas Variabel Produktivitas Kerja 


\section{Al-Kharaj: Jurnal Ekonomi, Kenancyan E Bisuis Syariah}

Volume 4 No 3 (2022) 914-933 P-ISSN 2656-2871 E-ISSN 2656-4351

DOI: 10.47467/alkharaj.v4i3.751

\begin{tabular}{cccc}
\hline & $\begin{array}{c}\text { Cronbach's Alpha } \\
\text { Based on } \\
\text { Vtandarized Item }\end{array}$ & $\begin{array}{c}\text { Nilai } \\
\text { Kritis }\end{array}$ & Keterangan \\
\hline Trilogi Kepemimpinan & 0.652 & 0.6 & Reliabel \\
Kepuasan Kerja & 0.673 & 0.6 & Reliabel \\
Motivasi & 0.732 & 0.6 & Reliabel \\
Produktivitas kerja & & & \\
karyawan & 0.690 & 0.6 & Reliabel \\
\hline
\end{tabular}

Sumber: data diolah, 2021

Berdasarkan hasil uji reabilitas diatas pada tabel 1 menunjukkan bahwa semua variabel penelitian memiliki alpha cronbach $>0,6$.

\section{Uji Normalitas}

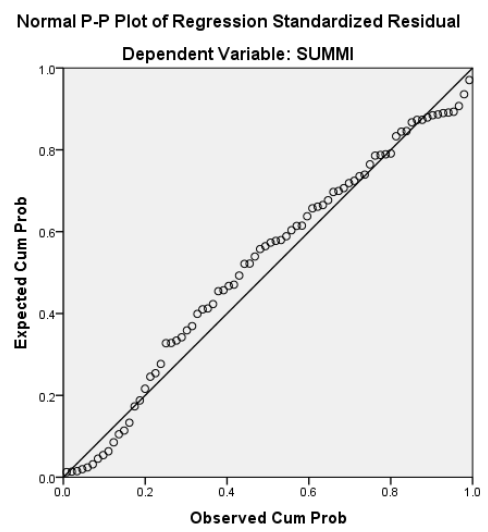

Gambar 2

Normalitas Trilogi Kepemimipinan, Kepuasan Kerja terhadap Motivasi

Sumber : data diolah, 2021

Berdasarkan hasil uji normalitas dari gambar 2 di atas dapat diperhatikan bahwa distibusi titik-titik di sumbu diagonal dari grafik P-P Plot normal variabel Trilogi Kepemimpinan, Kepuasan kerja terhadap Motivasi mengikuti adanya distribusi normal. Oleh sebab itu, model regresi memenuhi asumsi normalitas.

Tabel 2

Hasil Uji Normalitas Trilogi Kepemimipinan, Kepuasan Kerja terhadap Motivasi One-Sample Kolmogorov-Smirnov Test

\begin{tabular}{|lc|r|}
\hline & & $\begin{array}{r}\text { Unstandardiz } \\
\text { ed Residual }\end{array}$ \\
\hline $\mathrm{N}$ & 78 \\
Normal Parametersa,b & Mean & .0000000
\end{tabular}




\section{Al-Kharaj: Jurnal Ekonomi, Kenancyan E Bisuis Syariah}

Volume 4 No 3 (2022) 914-933 P-ISSN 2656-2871 E-ISSN 2656-4351

DOI: 10.47467/alkharaj.v4i3.751

\begin{tabular}{|ll|r|} 
& Std. & 3.36960925 \\
& Deviation & \\
Most Extreme & Absolute & .086 \\
Differences & Positive & .065 \\
& Negative & -.086 \\
Test Statistic & & .086 \\
Asymp. Sig. (2-tailed) & & $.200^{\mathrm{c}, \mathrm{d}}$ \\
\hline
\end{tabular}

a. Test distribution is Normal.

b. Calculated from data.

c. Lilliefors Significance Correction.

d. This is a lower bound of the true significance.

Sumber: data diolah, 2021

Pada hasil uji normalitas diatas pada tabel 2 menggunakan normal P-P plot dan uji Kolmogorov-smirnov dapat dilihat nilai asymp. sig (2-tailed) dengan nilai 0.200 untuk model regresi Trilogi Kepemimipinan, Kepuasan kerja terhadap Motivasi lebih besar 0,05 artinya data berdistribusi normal.

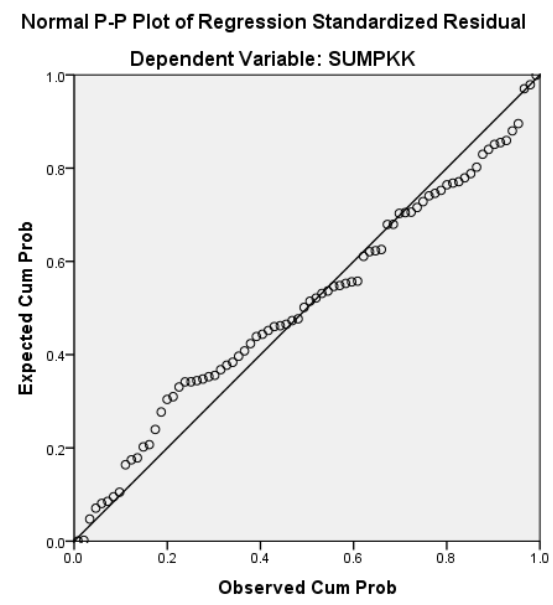

Gambar 3

Normalitas Trilogi Kepemimpinan, Kepuasan Kerja, Motivasi terhadap Produktifitas Kerja Karyawan

Sumber: data diolah, 2021

Berdasarkan hasil uji normalitas diatas pada gambar 3 diatas dapat diketahui bahwa penyebaran titik di sumbu diagonal dari grafik normal P-P Plot variabel Trilogi Kepemimpinan, Kepuasan Kerja, Motivasi terhadap Produktifitas Kerja Karyawan mengikuti adanya distribusi normal. Oleh karena itu, model regresi memenuhi asumsi normalitas.

Tabel 4 


\section{Al-Kharaj: Jurnal Ékonomi, Kenangan \& Bisnis Syariah}

Volume 4 No 3 (2022) 914-933 P-ISSN 2656-2871 E-ISSN 2656-4351

DOI: 10.47467/alkharaj.v4i3.751

\section{Hasil Uji Normalitas Trilogi Kepemimpinan, Kepuasan kerja, Motivasi terhadap}

Produktifitas Kerja Karyawan One-Sample Kolmogorov-Smirnov Test

\begin{tabular}{|ll|r|}
\hline & & $\begin{array}{r}\text { Unstandardiz } \\
\text { ed Residual }\end{array}$ \\
\hline $\mathrm{N}$ & & 78 \\
Normal Parameters ${ }^{\mathrm{a}, \mathrm{b}}$ & Mean & .0000000 \\
& Std. Deviation & 1.46219806 \\
Most Extreme & Absolute & .110 \\
Differences & Positive & .072 \\
& Negative & -.110 \\
Test Statistic & & .110 \\
Asymp. Sig. (2-tailed) & & $.200^{c}$ \\
\hline
\end{tabular}

a. Test distribution is Normal.

b. Calculated from data.

c. Lilliefors Significance Correction.

Sumber: data diolah, 2021

Berdasarkan hasil uji normalitas diatas pada tabel 4 menggunakan normal P-P plot dan uji Kolmogorov-smirnov dapat dilihat nilai asymp. sig (2-tailed) dengan nilai 0.200 untuk model regresi Trilogi Kepemimpinan, Kepuasan Kerja, Motivasi terhadap Produktifitas Kerja Karyawan lebih besar 0,05 artinya data berdistribusi normal.

\section{Uji Multikoloniaristas}

Analisis terhadap masalah multikolinieritas dilakukan dengan melihat nilai variante inflation factor (VIF), bila nilai VIF yang diamati >10 maka diduga terjadi masalah multikolinieritas.

Tabel 5

Hasil Uji Multikolinieritas Coefficients $^{\mathrm{a}}$

\begin{tabular}{|c|c|c|c|c|}
\hline \multirow[b]{2}{*}{ Model } & & \multicolumn{2}{|c|}{ Collinearity Statistics } & \\
\hline & & Tolerance & VIF & \\
\hline \multirow[t]{5}{*}{1} & (Constant) & & & \\
\hline & SUMTK & & & Tidak ada \\
\hline & \multirow{3}{*}{ SUMKK } & .882 & 1.133 & $\begin{array}{l}\text { Multikolinearit } \\
\text { as }\end{array}$ \\
\hline & & & & Tidak ada \\
\hline & & .882 & 1.133 & $\begin{array}{l}\text { Multikolinearit } \\
\text { as }\end{array}$ \\
\hline
\end{tabular}




\section{A1-Kharaj: Jurual Ekonomi, Kenaungan \& Bisnis Syariah \\ Volume 4 No 3 (2022) 914-933 P-ISSN 2656-2871 E-ISSN 2656-4351 \\ DOI: 10.47467/alkharaj.v4i3.751}

a. Dependent Variable: SUMMI

Dependen Variabel : Motivasi

Sumber: data diolah, 2021

Berdasarkan hasil uji multikolinieritas diatas pada tabel 5 menunjukkan bahwa variabel independen pada pengaruh Trilogi Kepemimpinan dan Kepuasan Kerja terhadap Motivasi nilai tolerance $.882>0,10$ atau sama dengan nilai VIF $1.133<10$, berarti tidak ada multikolinearitas antar variabel dalam model regresi.

Tabel 6

Hasil Uji Multikolinieritas

Collinearity Statistics

\begin{tabular}{|c|c|c|c|}
\hline Variabel & Tolerance & VIF & Keterangan \\
\hline Trilogi & & & Tidak terdapat \\
\hline Kepemimpinan & .858 & 1.166 & Multikolinearitas \\
\hline Kepuasan Kerja & .783 & 1.277 & $\begin{array}{l}\text { Tidak terdapat } \\
\text { Multikolinearitas }\end{array}$ \\
\hline Motivasi & .817 & 1.224 & $\begin{array}{l}\text { Tidak terdapat } \\
\text { Multikolinearitas }\end{array}$ \\
\hline
\end{tabular}

a. Dependen variabel: Produktifitas kerja karyawan

Sumber : Data diolah, 2021

Berdasarkan hasil uji multikolinieritas diatas pada tabel 6 menunjukkan Trilogi Kepemimpinan terhadap produktifitas kerja nilai tolerans $0.856>0,10$ atau sama memakai nilai VIF $1.166<10$, Kepuasan Kerja terhadap Produktifitas kerja nilai tolerans $0.783>0,10$ atau sama memakai nilai VIF $1.277<10$ dan Motivasi terhadap Produktifitas kerja nilai tolerans $0.817>0,10$ atau sama memakai nilai VIF $1.224<10$, sehingga tidak terdapat multikolinieritas antar variabel dalam model regresi.

\section{Uji Heterokedastisitas}

Uji glejser digunakan untuk mendeteksi ada tidaknya heteroskedastisitas. Jika signifikansi hasil korelasi lebih kecil dari 0,05 (5\%) maka persamaan pada contoh tersebut mengandung heteroskedastisitas, serta kebalikannya jika signifikansi hasil korelasi lebih dari 0,05 (5\%), maka berarti mengandung homoskedastisisitas atau tidak ada heterokedastisitas. 


\section{A1-Kharaj: Jurual Ekonomi, Kenangan \& Bisnis Syariah \\ Volume 4 No 3 (2022) 914-933 P-ISSN 2656-2871 E-ISSN 2656-4351 \\ DOI: 10.47467/alkharaj.v4i3.751}

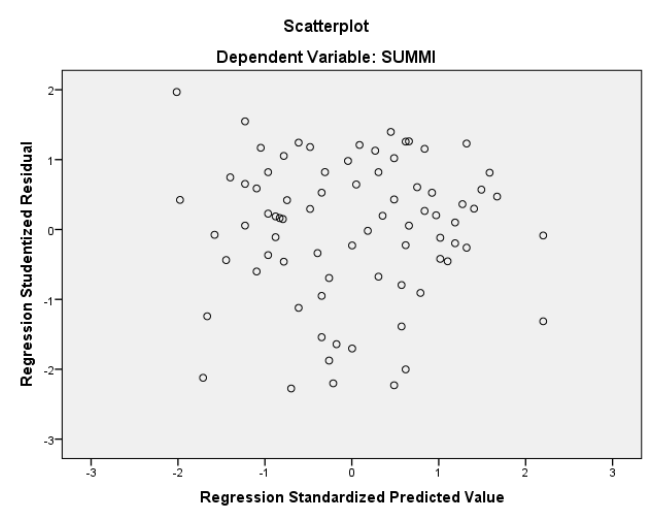

Gambar 4

Grafik Scatterplot Pengaruh Trilogi Kemimpinan Dan Kepuasan Kerja Terhadap Motivasi Sumber : data diolah, 2021

Berdasarkan hasil uji heteroskedastisitas diatas pada gambar 4 menunjukkan bahwa titik-titik pada scatter plot menyebar ke kiri dan kanan dari titik 0 pada sumbu $X$, dan menyebar ke bawah pada sumbu Y, dan tidak ada pola tertentu yang menunjukkan bahwa tidak ada tanda heteroskedastisitas dalam regresi.

Dalam penelitian ini peneliti juga melakukan uji statistik menggunakan uji glejser dengan nilai probabilitas signifikan $>0,05$. Uji glejser pada penelitian ini dapat dilihat di tabel 7.

Tabel 7

Hasil Uji Heterokedastisitas

Coefficients ${ }^{\mathrm{a}}$

\begin{tabular}{|rl|r|r|}
\hline \multicolumn{2}{|l|}{} & \multicolumn{1}{|c|}{ Model } & \multicolumn{1}{c|}{ Sig. } \\
\hline 1 & (Constant) & 1.748 & .085 \\
& SUMTK & .537 & .593 \\
& SUMKK & -1.642 & .105 \\
\hline
\end{tabular}

a. Dependent Variable: ABS_RES1

Sumber : data diolah, 2021

Berdasarkan hasil uji statistik heteroskedastisitas diatas pada tabel 7 dinyatakan bahwa nilai signifikansi variabel independen diatas 0,05. Maka dapat disimpulkan bahwa tak terjadi heteroskedastisitas pada contoh regresi ini. Hal ini konsisten dengan uji grafik scatterplot. 


\section{Al-Kharaj: Jurnal Ekonomi, Kenangan \& Bisnis Syariah}

Volume 4 No 3 (2022) 914-933 P-ISSN 2656-2871 E-ISSN 2656-4351

DOI: 10.47467/alkharaj.v4i3.751

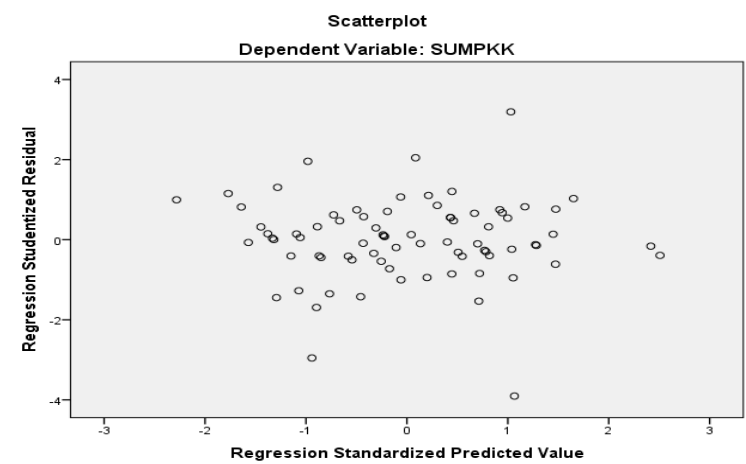

Gambar 5

Scatterplot pengaruh Trilogi kepemimpinan, Kepuasan kerja dan Motivasi Terhadap Produktifitas kerja karyawan Sumber: data diolah, 2021

Pada gambar 5 di atas, titik-titik di scatter plot menyebar ke arah kiri dan kanan dari titik 0 di sumbu $X$, serta menyebar ke bawah di sumbu Y, dan tidak terdapat pola tertentu yang memberikan bahwa tidak terdapat tanda-tanda heteroskedastisitas dalam regresi.

Tabel 8

Hasil Uji Heteroskedastisitas

Coefficients ${ }^{a}$

\begin{tabular}{|rl|r|rr|}
\hline \multicolumn{2}{|l|}{} & \multicolumn{2}{|c|}{ T } & \multicolumn{2}{|c|}{ Sig. } \\
\hline 1 & (Constant) & .713 & .478 \\
& SUMTK & 1.642 & .105 \\
& SUMKK & -1.823 & .072 \\
& SUMMI & .155 & .877 \\
\hline
\end{tabular}

a. Dependent Variable: SUMLK

Sumber: data diolah, 2021

Berdasarkan hasil uji statistik heteroskedastisitas diatas pada tabel 8 menunjukkan bahwa nilai signifikansi variabel independen diatas 0,05. Maka dapat disimpulkan bahwa tidak terjadi heteroskedastisitas dalam model regresi ini. Hal ini konsisten dengan uji grafik scatterplot.

\section{Hasil Analisis Regresi Linier Berganda}

Hasil Analisis Regresi Pengaruh Trilogi kepemimpinan, Kepuasan Kerja terhadap Motivasi 


\section{Al-Kharaj: Jurual Ekonomi, Kenangan \& Bisnis Syariah}

Volume 4 No 3 (2022) 914-933 P-ISSN 2656-2871 E-ISSN 2656-4351

DOI: 10.47467/alkharaj.v4i3.751

Tabel 9

Hasil Analisis Regresi Trilogi Kepemimpinan, Kepuasan Kerja terhadap Motivasi Coefficients $^{a}$

\begin{tabular}{|c|c|c|c|c|c|}
\hline \multirow[b]{2}{*}{ Model } & \multicolumn{2}{|c|}{$\begin{array}{c}\text { Unstandardized } \\
\text { Coefficients }\end{array}$} & \multirow{2}{*}{$\begin{array}{c}\text { Standardiz } \\
\text { ed } \\
\text { Coefficient } \\
\text { s } \\
\text { Beta }\end{array}$} & \multirow[b]{2}{*}{$\mathrm{T}$} & \multirow[b]{2}{*}{ Sig. } \\
\hline & B & Std. Error & & & \\
\hline $\begin{array}{ll}1 & \text { (Consta } \\
& \text { nt) }\end{array}$ & 2.618 & 5.394 & & .485 & .629 \\
\hline SUMTK & .211 & .144 & .163 & 1.469 & .146 \\
\hline SUMKK & .559 & .181 & .343 & 3.088 & .003 \\
\hline
\end{tabular}

a. Dependent Variable: SUMMI

Sumber : Data diolah, 2021

Hipotesis 1 Analisis Regresi pengaruh Trilogi kepemimpinan terhadap Motivasi

Uji t digunakan untuk mengetahui pengaruh Trilogi kepemimpinan saja terhadap Motivasi. Uji t dilakukan dengan membandingkan nilai p value menggunakan $\alpha(5 \%)$.

Tingkat signifikansi variabel Trilogi kepemimpinan sebanyak 0,146 $(\mathrm{p}>0,05)$ serta $\mathrm{t}$ hitung sebanyak 1.469 (positif) sehingga dapat diringkas bahwa t tabel $>$ t hitung (1.9916 $>1.469$ ) serta signifikansi $0,146 / 2=0.73>0,05$, maka hipotesis 1 ditolak.

\section{Hasil Analisis Regresi Pengaruh Kepuasan Kerja terhadap Motivasi}

Uji t digunakan untuk mengetahui pengaruh Kepuasan kerja saja terhadap Motivasi. Uji t dilakukan dengan membandingkan antara nilai $p$ value menggunakan $\alpha(5 \%)$.

Taraf signifikansi variabel Kepuasan Kerja sebanyak 0,003 ( $<<0,05)$ serta t hitung sebanyak 3.088 (Positif) sehingga bisa diringkas bahwa t tabel $<\mathrm{t}$ hitung $(1.9916<$ 3.088) serta signifikansi 0,003/2=0.001 >0,05, maka hipotesis 2 diterima.

Hasil Analisis Regresi Pengaruh Trilogi Kepemimpinan, Kepuasan Kerja, Motivasi terhadap Produktifitas Kerja Karyawan

Analisis regresi digunakan untuk menganalisis pengaruh Trilogi kepemimpinan, kepuasan kerja, motivasi terhadap produktifitas kerja karyawan. Hasil Uji 3 pada analisis regresi linear dapat dilihat pada tabel berikut ini.

Tabel 10

Hasil Analisis Regresi Antara Trilogi Kepemimpinan, Kepuasan Kerja, Motivasi terhadap Produktifitas Kerja Karyawan 


\section{Al-Kharaj: Jurnal Ekonomi, Kenangan \& Bisnis Syariah \\ Volume 4 No 3 (2022) 914-933 P-ISSN 2656-2871 E-ISSN 2656-4351 \\ DOI: 10.47467/alkharaj.v4i3.751}

\section{Coefficients ${ }^{\mathbf{a}}$}

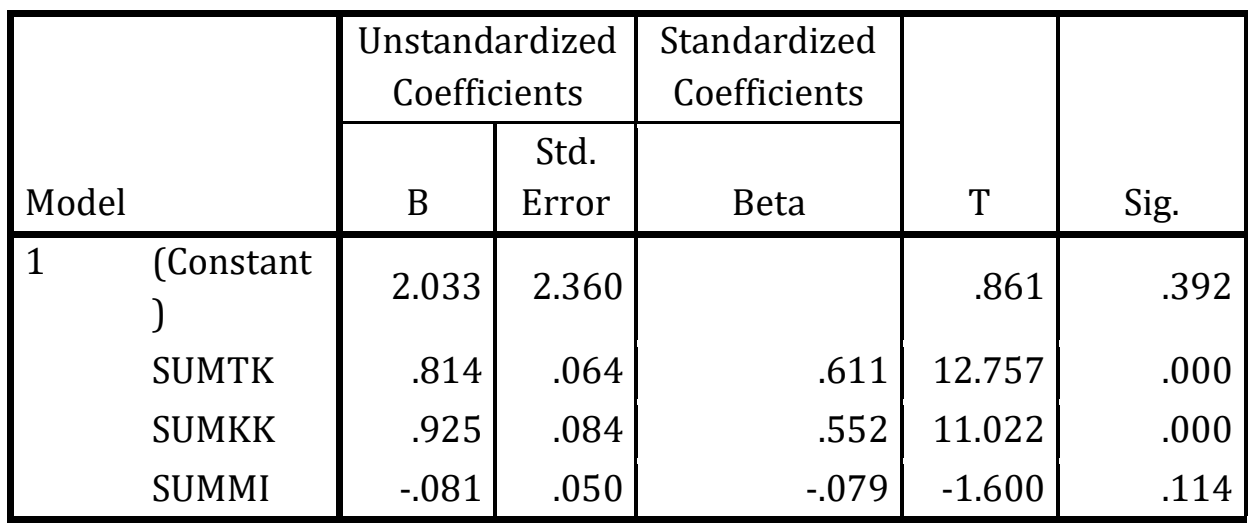

a. Dependent Variable: SUMPKK

Sumber : Data diolah, 2021 (Lampiran 6)

Trilogi kepemimpinan berpengaruh positif dan signifikan terhadap produktifitas kerja karyawan, sebanyak $0,000(\mathrm{p}<0,05)$ sert $\mathrm{t}$ hitung sebanyak 12.754 (positif), maka bisa diringkas bahwa t tabel $<$ t hitung $(1.9916<12.754)$ serta signifikansi $0,000 / 2=0.000<$ 0,05 .

Kepuasan kerja berpengaruh positif dan signifikan terhadap Produktifitas kerja karyawan, sebanyak 0,000 $(\mathrm{p}<0,05)$ serta t hitung sebesar 11.022 (positif), maka bisa diringkas bahwa $t$ tabel $<\mathrm{t}$ hitung $(1.9916>11.022)$ serta signifikansi $0,000 / 2=0.000<$ 0,05 .

Motivasi berpengaruh tidak signifikan terhadap Produktifitas kerja karyawan, sebanyak 0,114 ( $>00,05)$ serta $t$ hitung sebesar -1.600 (Negatif), maka bisa diringkas bahwa t tabel $>$ t hitung $(1.9916>-1.600)$ serta signifikansi $0,114 / 2=0.57>0,05$.

\section{Uji Sobel Tes}

Pada penelitian ini 2 hipotesis di uji menggunakan sobel tes Sobel, (1982) yaitu hipotesis 6 serta hipotesis 7 menggunakan hasil sebagai berikut: 


\section{Al-Kharaj: Jurnal Ekonomi, Kenancyan E Bisuis Syariah}

Volume 4 No 3 (2022) 914-933 P-ISSN 2656-2871 E-ISSN 2656-4351

DOI: 10.47467/alkharaj.v4i3.751

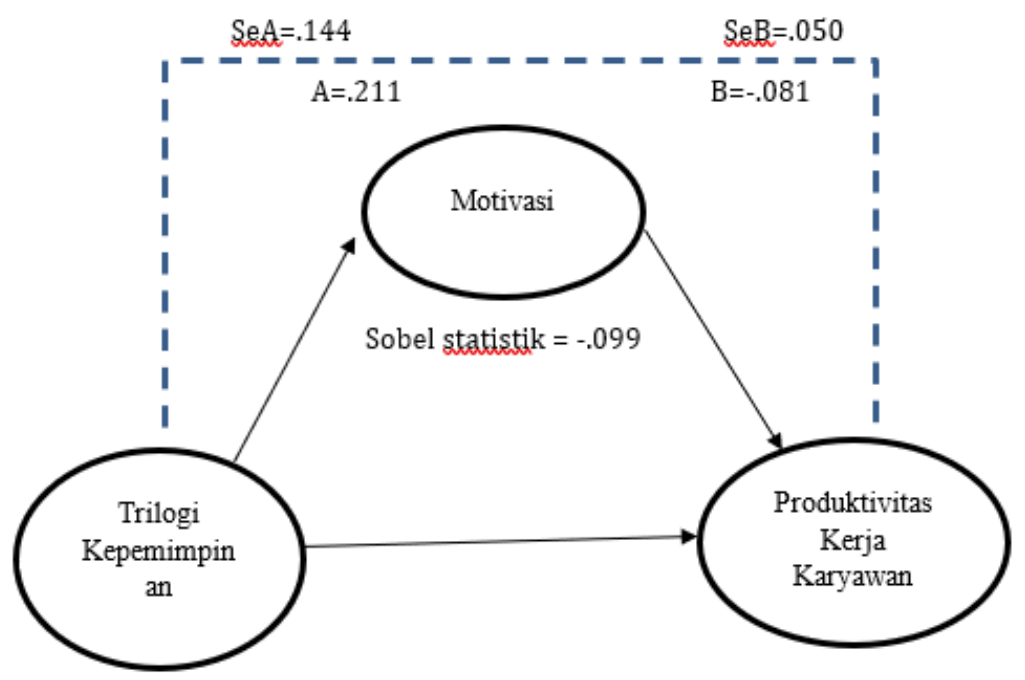

Gambar 6

Hasil Analisis Sobel Tes Hipotesis 6 dan Pembahasannya

$$
\begin{gathered}
Z=\frac{a b}{\sqrt{\left(b^{2} S E a^{2}\right)+\left(a^{2} S E b^{2}\right)}} \\
\frac{(0,211 X-0.081)}{\sqrt{\left(-0.081^{2} 0,144^{2}\right)+\left(0,211^{2} 0,050^{2}\right)}} \\
Z=-0.099
\end{gathered}
$$

Dari hasil perhitungan sobel tes diatas, mendapatkan nilai Z skor sebanyak $-0.099<$ 1,96 dengan taraf signifikansi 5\% maka membuktikan bahwa Motivasi tidak mampu memediasi Trilogi Kepemimpinan terhadap Produktivitas Kerja Karyawan.

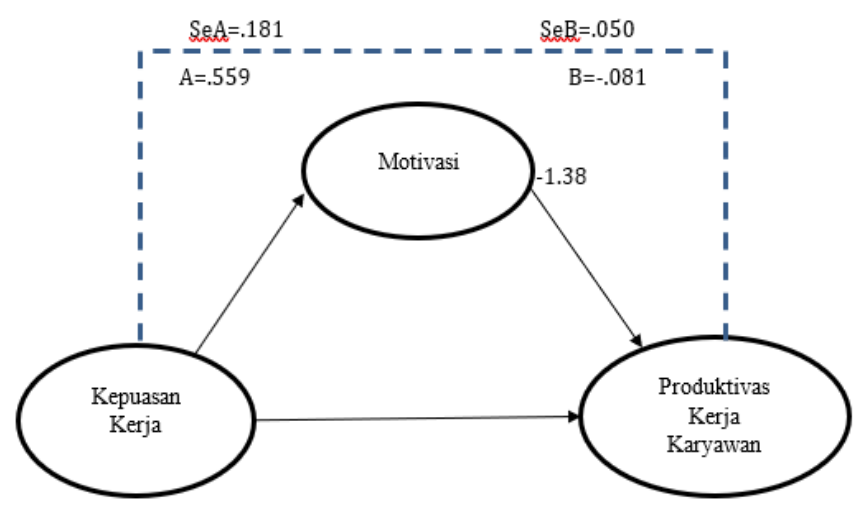

Gambar 7

Hasil Analisis Sobel Tes Hipotesis 7 dan Pembahasannya 


\section{Al-Kharaj: Jurnal Ekmonomi, Kenangan \& Bisnis Syariah}

Volume 4 No 3 (2022) 914-933 P-ISSN 2656-2871 E-ISSN 2656-4351

DOI: $10.47467 /$ alkharaj.v4i3.751

$$
Z=\frac{\frac{a b}{\sqrt{\left(b^{2} S E a^{2}\right)+\left(a^{2} S E b^{2}\right)}}}{\sqrt{(0,559 X-0,081)}}
$$

Dari hasil perhitungan sobel tes diatas, mendapatkan nilai Z skor sebesar $-1.38<1,96$ dengan tingkat signifikansi 5\% maka membuktikan bahwa Motivasi tidak mampu memediasi Kepuasan Kerja terhadap Produktivitas Kerja Karyawan.

\section{Koefisien Determinasi (Adjusted R square)}

Koefisien determinasi $\left(R^{2}\right)$ digunakan untuk mengukur seberapa jauh kemampuan model dalam menerangkan variasi variabel dependen Author et al., (2016). Nilai koefisien determinasi merupakan nol (0) dan satu (1). Nilai $\left(R^{2}\right)$ yang kecil berarti dependen amat terbatas. Nilai yang mendekati satu (1) berarti variabel-variabel independen memberikan hampir semua informasi yang dibutuhkan untuk memprediksi variasi variabel dependen.

a. Koefisisen Determinasi $\left(R^{2}\right)$ Trilogi Kepemimpinan dan Kepuasan Kerja terhadap Motivasi.

Tabel 11

Hasil Analisis Koefisisen Determinasi $\left(R^{2}\right)$ Trilogi Kepemimpinan dan Kepuasan Kerja terhadap Motivasi.

Model Summaryb

\begin{tabular}{|l|r|r|r|r|}
\hline Model & R & R Square & $\begin{array}{c}\text { Adjusted R } \\
\text { Square }\end{array}$ & $\begin{array}{c}\text { Std. Error of } \\
\text { the Estimate }\end{array}$ \\
\hline 1 & $.428^{\mathrm{a}}$ & .183 & .161 & 3.414 \\
\hline
\end{tabular}

a. Predictors: (Constant), SUMKK, SUMTK

b. Dependent Variable: SUMMI

Berdasarkan tabel 11 diketahui bahwa variabel independen mempengaruhi variabel dependen sebesar 0.161 (16.1\%) ditinjau dari kolom Adjusted R Square. Hasil ini menunjukkan bahwa masih terdapat faktor-faktor lain yang mempengaruhi motivasi yaitu sisanya sebanyak (83.9\%) diterangkan dari variabel lain yang tidak di jangkau pada penelitian ini.

b. Koefisisen Determinasi ( $R^{2}$ ) Trilogi Kerpemimpinan, Kepuasan Kerja, dan Motivasi terhadap Produktifitas Kerja Karyawan

Tabel 12

Hasil Analisis Koefisien Determinasi Trilogi Kepemimpinan, Kepuasan Kerja, Motivasi Terhadap Produktifitas Kerja Karyawan. 


\section{Al-Kharaj: Jurnal Ékonomi, Kenangan \& Bisnis Syariah}

Volume 4 No 3 (2022) 914-933 P-ISSN 2656-2871 E-ISSN 2656-4351

DOI: 10.47467/alkharaj.v4i3.751

Model Summaryb

\begin{tabular}{|l|r|r|r|r|}
\hline Model & R & R Square & \multicolumn{1}{|c|}{$\begin{array}{c}\text { Adjusted R } \\
\text { Square }\end{array}$} & $\begin{array}{l}\text { Std. Error of } \\
\text { the Estimate }\end{array}$ \\
\hline 1 & $.924^{\mathrm{a}}$ & .854 & .849 & 1.492 \\
\hline
\end{tabular}

a. Predictors: (Constant), SUMMI, SUMTK, SUMKK

b. Dependent Variable: SUMPKK

Berdasarkan tabel 12 diketahui bahawa variabel independen mempengaruhi variabel dependen sebesar 0,849 (84.9\%) ditinjau dari kolom Adjusted R Square. Hasil ini menunjukkan bahwa masih terdapat faktor-faktor lain yang mempengaruhi motivasi yaitu sisanya sebanyak (51.1\%) diterangkan dari variabel lain yang tidak di jangkau pada penelitian ini.

\section{Variabel Dominan (Beta Standarized)}

Tabel 13

\section{Hasil Uji Beta Standarized}

\begin{tabular}{|ll|r|r|r|}
\hline \multirow{2}{*}{ Model } & \multicolumn{2}{|c|}{ Unstandardized Coefficients } & $\begin{array}{c}\text { Standardized } \\
\text { Coefficients }\end{array}$ \\
\cline { 3 - 5 } & \multicolumn{1}{|c|}{ B } & Std. Error & \multicolumn{2}{c|}{ Beta } \\
\hline 1 & (Constant) & 2.033 & 2.360 & \\
& SUMTK & .814 & .064 & .611 \\
& SUMKK & .925 & .084 & .552 \\
& SUMMI & -.081 & .050 & -.079 \\
\hline
\end{tabular}

Berdasarkan Tabel 13 hasil regresi diketahui nilai beta $(\beta)$ yang paling berpengaruh terhadap variabel Produktifitas kerja karyawan (dependen) adalah variabel Trilogi Kepemimpinan sebesar .611, sebab nilai beta $(\beta)$ semakin menjauhi 0, sebagai akibat Trilogi Kepemimpinan merupakan variabel yang paling berpengaruh secara positif. Selanjutnya di ikuti variabel Kepuasan Kerja sebanyak .552, serta variabel Motivasi sebanyak -.079.

\section{Pembahasan}

\section{Trilogi Kepemimpinan terhadap Motivasi}

Pengujian hipotesis pertama menunjukkan ada pengaruh tidak signifikan Trilogi Kepemimpinan terhadap Motivasi kerja dengan koefisien sebesar 0.73 artinya lebih dari 0,05, maka hipotesis 1 ditolak. Hasil penelitian ini menandakan bahwa meskipun Trilogi Kepemimpinan dipersepsikan baik oleh karyawan PT. Mataram Tunggal Garment seperti pengaruh motivasi inspirasional, ideal, dan stimultan intelektual, namun ternyata hal 


\section{Al-Kharaj: Jurnal Ekonomi, Kenangan \& Bisnis Syariah \\ Volume 4 No 3 (2022) 914-933 P-ISSN 2656-2871 E-ISSN 2656-4351 \\ DOI: 10.47467/alkharaj.v4i3.751}

tersebut tidak berdampak konkret terhadap motivasi kerja. Pada hal ini, baik atau tidaknya pelaksanaan trilogi kepemimpinan para karyawan tetap termotivasi untuk bekerja.

\section{Kepuasan Kerja terhadap Motivasi}

Pengujian hipotesis kedua menunjukkan terdapat pengaruh signifikan Kepuasan kerja terhadap terhadap motivasi PT. Mataram Tunggal Garment. Hasil uji ini berdasarkan uji t sebesar 0.001 lebih besar dari 0,05, maka uji tersebut berpengaruh positif. Artinya jika terjadi kenaikan kepuasan kerja, maka akan diikuti oleh motivasi kerja karyawan pada PT. Mataram Tunggal Garment. Kepuasan kerja yang dirasakan oleh karyawan pada umumnya menggambarkan pada perilaku positif karyawan terhadap pekerjaan serta segala sesuatu yang dihadapi ataupun yang ditugaskan kepadanya di lingkungan kerja. Kebalikanya jika kepuasan kerja tidak tercapai maka dapat mengakibatkan buruk terhadap perusahaan. Dampak buruk itu berupa kemalasan, mogok kerja, pergantian tenaga kerja serta dampak buruk yang merugikan lainnya.

\section{Trilogi Kepemimpinan terhadap Produktifitas Kerja}

Pengujian hipotesis ketiga menunjukkan menunjukan terdapat pengaruh signifikan Trilogi kepemimpinan terhadap produktifitas kerja PT. Mataram Tunggal Garment. Dalam keadaan normal, setiap pimpin tidak bisa memilih sendiri skala gaji yang berlaku untuk unitnya. Tetapi, setiap manajer mempunyai kewajiban untuk menilai apakah posisi di bawah pengawasannya dibayar untuk pekerjaan yang mereka lakukan, bagaimana posisi di tempat kerja diklarifikasikan, serta faktor apa yang memilih klasifikasi. Selain itu, adanya imbalan perusahaan terhadap produktivitas kerja yang ditunjukkan oleh karyawan mampu memberikan dorongan agar dapat memberikan hasil yang baik dan semakin baik kedepannya.

\section{Kepuasan Kerja terhadap Produktifitas Kerja Karyawan}

Pada hasil hipotesis keempat menunjukkan Kepuasan kerja berpengaruh positif serta signifikan terhadap Produktifitas kerja Karyawan PT. Mataram Tunggal Garmet. Hal ini dapat dibuktikan dengan hasil analisis regresi linier berganda yang juga menunjukkan bahwa kepuasan kerja berpengaruh positif dan signifikan terhadap produktivitas kerja. Pada hal ini, jika variabel kepuasan naik, maka variabel produktivitas kerja akan semakin tinggi sebanyak $0.000<0,05$, sehingga dapat diterima. Adanya kepuasan pada diri seseorang akan menaikkan produktivitas kerja jika perusahaan menyampaikan umpan balik terhadap hasil yang telah dikerjakan oleh karyawan tersebut.

\section{Motivasi terhadap Produktifitas Kerja Karyawan}

Pengujian hipotesis kelima menunjukkan tidak berpengaruh Motivasi terhadap Produktivitas Kerja PT. Mataram Tunggal Garment. Pada hal ini, bila variabel motivasi 


\section{Al-Kharaj: Jurnal Ekonomi, Kenangan \& Bisnis Syariah \\ Volume 4 No 3 (2022) 914-933 P-ISSN 2656-2871 E-ISSN 2656-4351 \\ DOI: 10.47467/alkharaj.v4i3.751}

turun, maka variabel produktivitas kerja akan mengalami turun sebanyak $0.57>0,05$, sehingga ditolak. Produktivitas kerja karyawan yang dinilai tidak memuaskan, sering disebabkan oleh motivasi yang rendah, motivasi melibatkan keinginan seseorang untuk menunjukkan kemampuan dalam bekerja. Sehingga pernyataan ini dapat dikatakan bahwa peningkatan motivasi dalam diri seorang karyawan pada suatu perusahaan sangat penting untuk mencapai produktivitas kerja yang optimal sehingga mencapai tujuan perusahaan.

\section{Motivasi Memediasi Trilogi Kepemimpinan terhadap Produktifitas Kerja Karyawan}

Pengujian hipotesis keenam menunjukkan bahwa adanya pengaruh yang tidak signifikan Motivasi memediasi Trilogi Kepemimpinan terhadap Produktivitas Kerja Karyawan dengan Motivasi sebagai variabel mediasi karyawan pada PT. Mataram Tunggal Garment. Sehingga hipotesis menolak bahwa kepemimpinan akan menyebabkan peningkatkan motivasi kerja, maka tidak ada peran mediasi motivasi kerja terhadap trilogi kepemimpinan dengan produktivitas kerja karyawan. Hal ini dibuktikan dengan olah data menggunakan Sobel Tes, mendapatkan nilai Z skor sebesar $-0.099<1,96$ menggunaka taraf signifikansi 5\% maka menujukkan bahwa Motivasi tidak mampu memediasi Trilogi Kepemimpinan terhadap Produktivitas Kerja Karyawan.

\section{Motivasi Memediasi Kepuasan Kerja Terhadap Produktifitas Kerja Karyawan dengan Motivasi Sebagai Variabel Mediasi}

Pengujian hipotesis ketujuh menunjukkan tidak berpengaruh Kepuasan Kerja terhadap Produktivitas Kerja Karyawan dengan Motivasi sebagai variabel mediasi karyawan pada PT. Mataram Tunggal Garment. Hal ini dibuktikan dengan olah data menggunakan Uji Sobel Tes, mendapatkan nilai Z skor sebesar $-1.38<1$,96 dengan tigkat signifikansi 5\% maka membuktikan bahwa Motivasi tidak mampu memediasi Kepuasan Kerja terhadap Produktivitas Kerja Karyawan, artinya semakin puas terhadap produktivitas kerja maka semakin cenderung motivasi kerjanya akan menurun.

\section{KESIMPULAN DAN SARAN}

\section{Kesimpulan}

Berdasarkan hasil analisis yang sudah dibahas di bab sebelumnya, dapat diberikan kesimpulan sebagai berikut :

1. Trilogi Kepemimpinan terhadap Motivasi berpengaruh tidak signifikan pada Karyawan PT. Mataram Tunggal Garment.

2. Kepuasan Kerja terhadap Motivasi berpengaruh signifikan pada karyawan PT. Mataram Tunggal Garment. 


\section{Al-Kharaj: Jurual Ékonomi, Kenanczan \& Bisnis Syariah \\ Volume 4 No 3 (2022) 914-933 P-ISSN 2656-2871 E-ISSN 2656-4351 \\ DOI: 10.47467/alkharaj.v4i3.751}

3. Trilogi Kepemimpinan terhadap Produktifitas Kerja Karyawan berpengaruh signifikan pada PT. Mataram Tunggal Garment.

4. Kepuasan Kerja terhadap Produktifitas Kerja Karyawan berpengaruh signifikan pada PT. Mataram Tunggal Garment.

5. Motivasi terhadap Produktifitas Kerja Karyawan berpengaruh tidak signifikan pada PT. Mataram Tunggal Garment.

6. Motivasi Memediasi Trilogi Kepemimpinan Terhadap terhadap Produktifitas Kerja Karyawan berpengaruh tidak signifikan pada karyawan pada PT. Mataram Tunggal Garment.

7. Motivasi Memediasi Kepuasan Kerja terhadap Produktifitas Kerja karyawan berpengaruh tidak signifikan pada PT. Mataram Tunggal Garment.

\section{DAFTAR PUSTAKA}

Ahyar, M. dan P. (2018). Trilogi Kepemimpinan dan Komitmen Organisasi dengan Organizational Citizenship Behavior sebagai variabel intervening (Studi kasus pada Pengurus Organisasi Kemahasiswaan Universitas Sarjanawiyata Tamansiswa Yogyakarta) M . Ahyar SL 1 dan Prayekti. Upajiwa, 2(1), 57-65.

AkAdely, A. P. (2018). Pengaruh Kepemimpinan Dan Kepuasan Kerja Terhadap Motivasi Kerja Karyawan: Studi Pada Bank Bjb Cabang Ciamis. Journal of Management Review, 2(1), 106. https://doi.org/10.25157/jmr.v2i1.913

Akpoviroro, K. S., Kadiri, B., \& Owotutu, S. O. (2018). Effect of participative leadership style on employees productivity. Trendy v Podnikání, 8(2), 47-60. https://doi.org/10.24132/jbt.2018.8.2.48_58

Alam, M. N., Hassan, M. M., Bowyer, D., \& Reaz, M. (2020). The effects of wages and welfare facilities on employee productivity: Mediating role of employee work motivation. Australasian Accounting, Business and Finance Journal, 14(4), 3860. https://doi.org/10.14453/aabfj.v14i4.4

Author, R., Review, P. W., Source, P. W., \& Url, B. S. (2016). Review Author(s): Paul Wernst Review by: Paul Wernst Source: 21, 10-11.

Bonaparte, E. (2017). Pengaruh Kepemimpinan Terhadap Motivasi dan Kinerja Karyawan pada Direktorat Jendral Administrasi dan Keuangan , Kementerian Estatal Timor Leste Fakultas Ekonomi dan Bisnis Universitas Udayana ( Unud ), Denpasar Bali ABSTRAK LATAR BELAKANG Agar aktivitas . 11, 3731-3764.

Ekhsan, M., \& Setiawan, I. (2021). The Role of Motivation Mediation on the Effect of Transformational Leadership Style on Employee Performance. International Journal of Management Science and Information Technology, 1(1), 35. https://doi.org/10.35870/ijmsit.v1i1.232

Gede, I. P., Iswara, D., Agung, A., \& Sriathi, A. (2016). Kerja Dan Komitmen Organisasional Terhadap Organizational Citizenship Behavior Di Pt . Bpd Bali. 5(9), 5923-5948. 


\section{Al-Kharaj: Jurual Ékonomi, Kenangan \& Bisnis Syariah \\ Volume 4 No 3 (2022) 914-933 P-ISSN 2656-2871 E-ISSN 2656-4351 \\ DOI: 10.47467/alkharaj.v4i3.751}

Hamali, A. Y. (2013). Pengaruh Motivasi terhadap Produktivitas Kerja: Studi Kasus $\begin{array}{lllll}\text { pada } \mathrm{PT} & \mathrm{X} \text { Bandung. The Winners, }\end{array}$ https://doi.org/10.21512/tw.v14i2.647

Harimisa, M. E., \& Fakultas. (2017). Kepemimpinan Dan Motivasi Kerja Pengaruhnya Terhadap Produktivitas Kerja Pegawai Di Kantor Camat Sario Kota Manado. Jurnal EMBA: Jurnal Riset Ekonomi, Manajemen, Bisnis Dan Akuntansi, 1(4), 2143-2154. https://ejournal.unsrat.ac.id/index.php/emba/article/view/3425/2969

Hestin Sri, D. A. (2017). Journal of Industrial Engineering \& Management Research. 6(1), 70-78.

Ilhami Wijaya, J., Hamid, D., \& Nayati Utami, H. (2017). Pengaruh Gaya Kepemimpinan Terhadap Motivasi Dan Kepuasan Kerja (Studi pada Kasubag di Lingkungan Universitas Brawijaya Malang). Profit, 11(02), 34-47. https://doi.org/10.21776/ub.profit.2017.011.02.4

Insentif, P., Kerja, K., Daya, D. A. N., \& Terhadap, S. (2018). Pengaruh Insentif, Kepuasan Kerja Dan Daya Saing Terhadap Produktivitas Kerja Karyawan Pada Ud. Jepara Karya Furniture, Kec Tuminting. Jurnal EMBA: Jurnal Riset Ekonomi, Manajemen, Bisnis Dan Akuntansi, 6(2), 638-647. https://doi.org/10.35794/emba.v6i2.19625

Karima, A. N. A., Idayanti, \& Umar, A. (2018). Effect of the Work, Training and Motivation To Employee Productivity At PT. Bank Sulselbar. Hjabe, 1(4), 8395.

Kerja, P., Cv, K., Lumajang, I., Adiwinata, I., Bisnis, P. M., Manajemen, P. S., Petra, U. K., \& Siwalankerto, J. (2014). Pengaruh Kepuasan Kerja Dan Motivasi Kerja Terhadap Rs $\square m \square n$ b. 2(1), 1-2.

Kridharta, D., \& Rusdianti, E. (2017). Analisis Pengaruh Karakteristik Individu, Komitmen Organisasi, Dan Kepuasan Kerja Terhadap Kinerja Karyawan Dengan Motivasi Sebagai Variabel Intervening. Jurnal Riset Ekonomi Dan Bisnis, 10(3), 232. https://doi.org/10.26623/jreb.v10i3.882

Maduka, C. E., \& Okafor, O. (2014). Effect of Motivation on Employee Productivity: A Study of Manufacturing Companies in Nnewi. International Journal of Managerial Studies and Research, 2(7), 137-147. www.arcjournals.org

Maida, M. T., Riyanto, S., \& Ali, H. (2017). Effect of Job Satisfaction and Leadership Style towards Employee Productivity at PT. Asuransi Umum Bumiputera Muda 1967. Saudi Journal of Business and ..., July 2020, 157-168. https://doi.org/10.21276/sjbms.2017.2.3.7

Mario, Y. El, \& Suhermin. (2017). Pengaruh Motivasi Dan Gaya Kepemimpinan Terhadap Produktivitas Kerja Karyawan. Jurnal Ilmu Dan Riset Manajemen, 06(03), 1-16. http://library1.nida.ac.th/termpaper6/sd/2554/19755.pdf

Marliani, L., \& Djadjuli, R. D. (2019). Menakar Trilogi Kepemimpinan Ki Hajar Dewantara Di Era Globalisasi. Kebijakan: Jurnal Ilmu Administrasi, 10(2), 74. https://doi.org/10.23969/kebijakan.v10i2.1654

Mayssara A. Abo Hassanin Supervised, A. (2014a). 済無No Title No Title No Title. Paper Knowledge . Toward a Media History of Documents, 1(3), 969-979. 


\section{Al-Kharaj: Jurual Ékonomi, Kenanczan \& Bisnis Syariah \\ Volume 4 No 3 (2022) 914-933 P-ISSN 2656-2871 E-ISSN 2656-4351 \\ DOI: 10.47467/alkharaj.v4i3.751}

Mayssara A. Abo Hassanin Supervised, A. (2014b). 済無No Title No Title No Title.

Paper Knowledge . Toward a Media History of Documents, 1(4), 1042-1052.

Muayyad, D. M., \& Gawi, A. I. O. (2017). Pengaruh Kepuasan Kerja Terhadap

Produktivitas Kerja Pegawai Bank Syariah X Kantor Wilayah Ii. Jurnal

$\begin{array}{llll}\text { Manajemen Dan Pemasaran } & \end{array}$

https://doi.org/10.25105/jmpj.v9i1.1396

Ninla Elmawati Falabiba. (2019). 済無No Title No Title No Title.

Pada, K., Nadi, P. T., \& Bumi, S. (2018). = 8098,471 > 3,160 atau ( F. 1(1), 66-82.

Putro, S., \& Havidz, M. (2019). The Effect of Compensation and Job Satisfaction On Increasing Productivity of Asuransi Jasindo Head Office Employees Mediated by Motivation Variable. International Journal of Innovative Science and Research Technology, 4(7), 100-113. www.ijisrt.com100

Rahmawati, D. (2013). Pengaruh Motivasi Terhadap Berlian Tulungagung. Jurnal Universitas Tulungagung Bonorowo, 1(1), 1-16.

Rumondor, V. (2013). Motivasi, Disiplin Kerja, Dan Kepemimpinan Terhadap Produktivitas Kerja Pada Badan Kepegawaian Dan Diklat Daerah Minahasa Selatan. Jurnal EMBA: Jurnal Riset Ekonomi, Manajemen, Bisnis Dan Akuntansi, 1(4), 1042-1052. https://doi.org/10.35794/emba.v1i4.2844

Saleh, A. R., \& Utomo, H. (2018). Pengaruh Disiplin Kerja, Motivasi Kerja, Etos Kerja Dan Lingkungan Kerja Terhadap Produktivitas Kerja Karyawan Bagian Produksi Di Pt. Inko Java Semarang. Among Makarti, 11(1), 28-50. https://doi.org/10.52353/ama.v11i1.160

Saputra, H. ; A. . (2020). Pengaruh Budaya Kerja Dan Kepuasan Kerja Terhadap Produktivitas Kerja Pegawai Pada Kanwil Kementerian Agama Provinsi Kalimantan Selatan. 4(2), 61-83. https://ejournal.stiabinabanuabjm.ac.id/index.php/administraus/article/view/96/7 4

Siswanto, R., \& Hamid, D. (2017). Pengaruh Gaya Kepemimpinan Terhadap Kinerja Karyawan (Studi pada karyawan divisi Human Resources Management Compensation and Benefits PT Freeport Indonesia). Jurnal Administrasi Bisnis S1 Universitas Brawijaya, 42(1), 189-198.

Sobel, M. E. (1982). Asymptotic Confidence Intervals for Indirect Effects in Structural Equation Models. Sociological Methodology, 13(1982), 290. https://doi.org/10.2307/270723

Sudanang, E. A., \& Priyanto, S. E. (2020). Pengaruh Kepuasan Kerja Dan Budaya Organisasi Terhadap Produktivitas Kerja Karyawan Di Horison Apartemen Dan Kondotel Yogyakarta. Kepariwisataan: Jurnal Ilmiah, 14(01), 31-36. https://doi.org/10.47256/kepariwisataan.v14i01.16

Sugiyono. (2019). Metode Penelitian Kuantitatif, Kualitatif, dan R\&D-MPKK.

Syska Lady Sulistyowati, R. W. P. (2018). Jurnal Bisnis Teori dan Implementasi,. Jurnal Bisnis Teori Dan Implementasi, 9(1), 13-21.

Wijayanti, W. (2019). Hal itu menunjukkan bahwa figure seorang pemimpin hendaknya memberi dan sekaligus menjadi contoh pada anak buahnya, serta 


\section{A1-Kharaj: Jurual Ekonomi, Kenangan \& Bisnis Syariah \\ Volume 4 No 3 (2022) 914-933 P-ISSN 2656-2871 E-ISSN 2656-4351 \\ DOI: 10.47467/alkharaj.v4i3.751}

ditengah-tengah mampu memberikan dorongan dan semangat bagi anggotanya. Jurnal Ustjogja, 2(2), 181-192.

Wulandari, W. C. (2017). Implementasi Trilogi Ki Hadjar Dewantara Dalam Kepemimpinan Kepala Sekolah di SD Negeri 1 Mergowati Kecamatan Kedu Kabupaten Temanggung. Prodi PGSD Universitas PGRI Yogyakarta. http://repository.upy.ac.id/1680/

Yuliannisa, S. N., Basrindu, G., \& Yani, A. (2018). Pengaruh Kompensasi Dan Motivasi Terhadap Produktivitas Kerja Di Pt Inter Pan Pasifik Futures. 2(1), 93106.

Zinnurain, Z., Asmony, T., \& Hermanto, H. (2017). Peran Mediasi Motivasi Dalam Pengaruh Tunjangan Kinerja Dan Kepemimpinan Terhadap Produktivitas (Studi Pada Pegawai Komisi Pemilihan Umum Kabupaten/Kota Se-Pulau Lombok). Jmm Unram Master of Management Journal, 6(1), 1-21. https://doi.org/10.29303/jmm.v6i1.249 